\title{
A case of long-term survival after splenectomy for solitary splenic metastasis from gastric cancer
}

\author{
Ayato Obana ${ }^{1,2^{*}}$ (D, Nobuo Komatsu', Kazuma Aiba ${ }^{1}$, Shinya Nakanishi ${ }^{1}$, Masakazu Abe ${ }^{1}$, Toshiyuki Yamaguchi ${ }^{1}$, \\ Masahiro Hayashi ${ }^{1}$, Hayato Obi ${ }^{1}$, Masamichi Koyama ${ }^{1}$ and Shinichi Hashimoto ${ }^{1}$
}

\begin{abstract}
Background: Very rarely does a splenic solitary metastasis arise from a gastric carcinoma because splenic metastasis is usually seen in association with widespread visceral metastasis. Splenectomy is considered to be a curative treatment; however, long-term prognosis after splenectomy has scarcely been reported. We report a case of a metachronous and solitary metastasis to the spleen from gastric cancer in which the patient achieved 5-year recurrence-free survival after splenectomy.

Case presentation: An 84-year-old man underwent an open total gastrectomy involving D1+ lymph nodes dissection for gastric cancer located in the cardia (pT3N1M0, pStage IIB). Eighteen months later, a 2-cm solitary hypodense lesion was detected in the spleen by computed tomography (CT). Twenty-three months later, the serum carcinoembryonic antigen (CEA) value elevated to $19.9 \mathrm{ng} / \mathrm{ml}$, and abdominal CT revealed an increase in tumor size to $5 \mathrm{~cm}$. Positron-emission tomography (PET)-CT revealed intense ${ }^{18} \mathrm{~F}$-2-deoxy-2-fluoro-glucose (FDG) uptake in the spleen without the involvement of other organs and lymph nodes. We diagnosed him with solitary splenic metastasis from gastric cancer and performed a splenectomy 26 months after the first surgery. Histological examination revealed that the splenic tumor was a moderately differentiated adenocarcinoma, which was very similar to the primary gastric tumor; the lesion was diagnosed as a metastatic tumor from the previous gastric carcinoma. The patient remains healthy to date without recurrence, 5 years after the splenectomy.

Conclusion: We experienced a case of a solitary splenic metastasis from gastric cancer in which 5-year recurrencefree survival was achieved after splenectomy. To determine the surgical indication in patients with splenic metastasis, it is important to differentiate between a solitary lesion or multiple metastasis. Especially, occult metastasis should be excluded by means of several months of follow-up with imaging tests and systemic FDG-PET surveys before splenectomy.
\end{abstract}

Keywords: Splenic metastasis, Gastric cancer, Splenectomy

\footnotetext{
* Correspondence: obanaayato@gmail.com; a.obana@kashiwakousei.or.jp

'Department of Surgery, Asama Nanroku Komoro Medical Center, Nagano,

Japan

2Department of General Surgery, Kashiwa Kousei General Hospital, 617,

Shikoda, Kashiwa, Chiba 277-8551, Japan
}

(c) The Author(s). 2020 Open Access This article is licensed under a Creative Commons Attribution 4.0 International License, which permits use, sharing, adaptation, distribution and reproduction in any medium or format, as long as you give appropriate credit to the original author(s) and the source, provide a link to the Creative Commons licence, and indicate if changes were made. The images or other third party material in this article are included in the article's Creative Commons licence, unless indicated otherwise in a credit line to the material. If material is not included in the article's Creative Commons licence and your intended use is not permitted by statutory regulation or exceeds the permitted use, you will need to obtain permission directly from the copyright holder. To view a copy of this licence, visit http://creativecommons.org/licenses/by/4.0/. The Creative Commons Public Domain Dedication waiver (http://creativecommons.org/publicdomain/zero/1.0/) applies to the data made available in this article, unless otherwise stated in a credit line to the data. 


\section{Background}

Splenic metastases from non-hematologic malignancies are quite rare [1] and usually found in association with widespread visceral metastases, according to large retrospective studies on autopsy cases [2,3]. Solitary splenic metastasis from gastric cancer is even rarer, and only few case reports have been published [4-14]. Those reports concluded that splenectomy could be a potential effective treatment for splenic solitary metastasis. However, all those case reports had a follow-up period of only a few years after the splenectomy, and no longterm prognosis has been reported. We herein report a successful surgical treatment case involving a metachronous solitary splenic metastasis from gastric cancer in which the patient achieved a favorable prognosis with 5year recurrence-free survival after the splenectomy.

\section{Case presentation}

An 84-year-old Japanese male patient was referred to our hospital for detailed examination for gastric cancer diagnosed at a routine medical check-up. Upper endoscopy was performed and an approximately $5-\mathrm{cm}$ wide type 1 tumor was detected in the cardiac region of the stomach (Fig. 1).

Biopsy showed moderately differentiated adenocarcinoma (tub2). No distant metastatic lesions were identified on enhanced abdominal computer tomography (CT) or chest CT. Laboratory data showed that tumor markers such as carcinoembryonic antigen (CEA) and carbohydrate antigen 19-9 (CA19-9) were within the normal limits. Accordingly, based on the Japanese gastric cancer treatment guideline [15], total gastrectomy with D2 lymph node dissection was indicated. However, considering his older age, total gastrectomy with D1+ regional

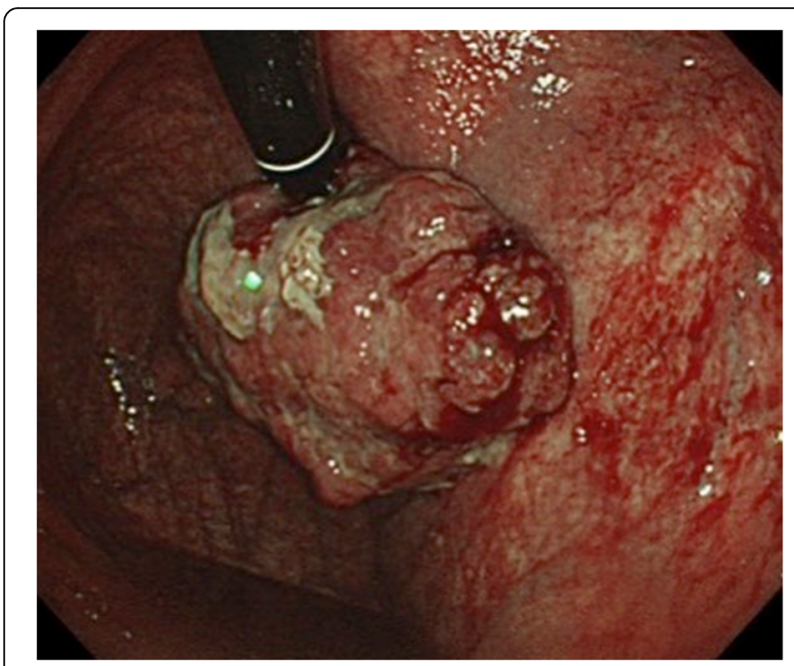

Fig. 1 Upper endoscopy detected approximately 5-cm-wide type 1 tumor in the cardia region of the stomach lymph node dissection was performed. The resected specimen revealed that the tumor was $48 \times 28 \mathrm{~mm}$ in diameter. Histological examination showed moderately differentiated adenocarcinoma infiltrating the subserosa with metastasis to 1 of 37 regional lymph nodes (a lymph node along the short gastric artery was positive) and slight lymphatic invasion; however, no venous invasion was identified.

According to the Japanese classification of gastric carcinoma 3rd English edition [16], the patient was diagnosed with pT3N1M0, ly1, v0, and pStage IIB. Postoperative course was uneventful, and the patient was discharged on postoperative day 17. Adjuvant chemotherapy with oral TS-1 was recommended, according to the Japanese gastric cancer treatment guideline [15]. However, considering his older age, this regimen was not performed and the patient was followed-up in the outpatient clinic.

The patient was assessed according to the Japanese gastric cancer treatment guideline, which was comprised of routine physical examinations, measurements of serum tumor markers such as CEA and CA 19-9 (every three months during the 5 years after the surgery), thoracoabdominal computed tomography (every 6 months during the first 3 years after the surgery and once every 12 months from the fourth year onward), and upper endoscopy $(1,3$, and 5 years after the surgery).

Eighteen months later, a 2-cm solitary hypodense lesion was detected in the spleen on $\mathrm{CT}$, but serum tumor markers remained within the normal limits. Twentythree months later, serum CEA elevated to 19.9 , and an abdominal $\mathrm{CT}$ revealed that the splenic lesion increased in size to about $5 \mathrm{~cm}$ (Fig. 2).

Splenic metastasis was suspected, and ${ }^{18} \mathrm{~F}$-2-deoxy-2fluoro-glucose (FDG) positron emission tomography-

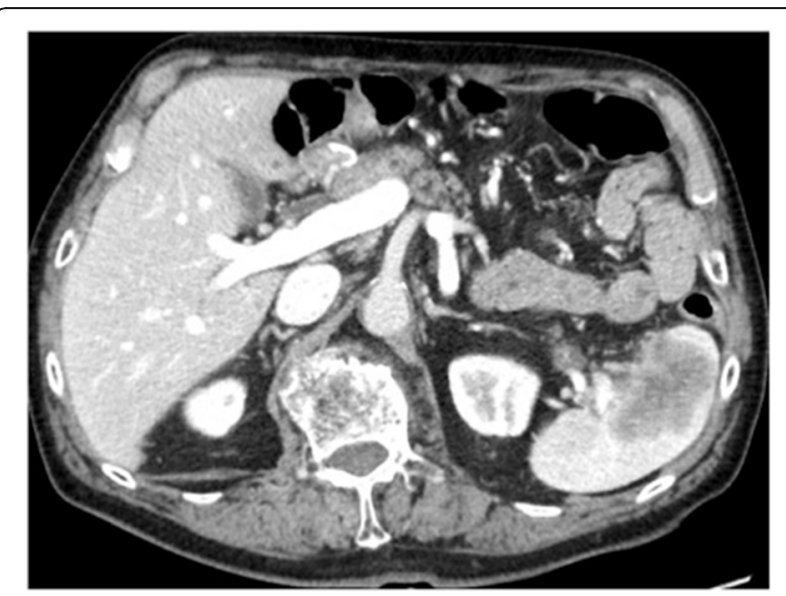

Fig. 2 A hypodense lesion (diameter $5 \mathrm{~cm}$ ) was identified on enhanced abdominal CT 23 months post-first surgery. CT, computed tomography 
CT (PET/CT) was scheduled to identify other metastatic sites besides the spleen. The PET-CT revealed intense FDG uptake in the spleen without involvement of other organs (Fig. 3). Upper endoscopy and colonoscopy were also performed, and no abnormalities were identified.

We diagnosed the patient with solitary splenic metastatic tumor from gastric cancer and thought the splenectomy could be an effective treatment to eliminate the tumor even though his age was 86 at that time. Therefore, the splenectomy was performed 26 months after the first surgery.

Resected specimen showed a well-circumscribed, white, $57 \times 51 \mathrm{~mm}$ in size, solid tumor located in the splenic parenchyma on cross-section. The tumor was demarcated from the splenic parenchyma without any capsule invasion (Fig. 4). Histological examination revealed

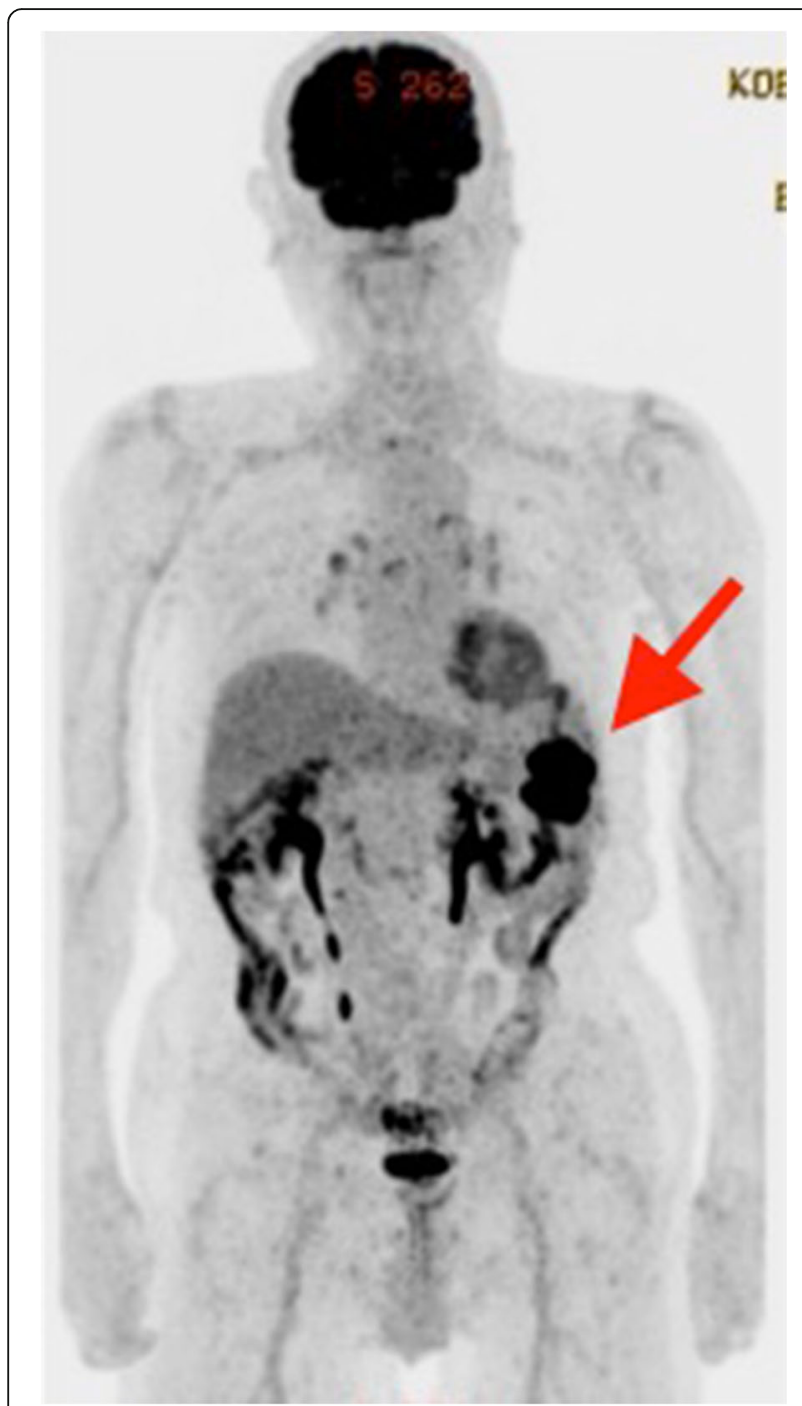

Fig. 3 FDG-PET-CT showing abnormal FDG accumulation in the spleen (red arrow).FDG, ${ }^{18}$ F-2-deoxy-2-fluoro-glucose, PET-CT, positron emission tomography-computed tomography

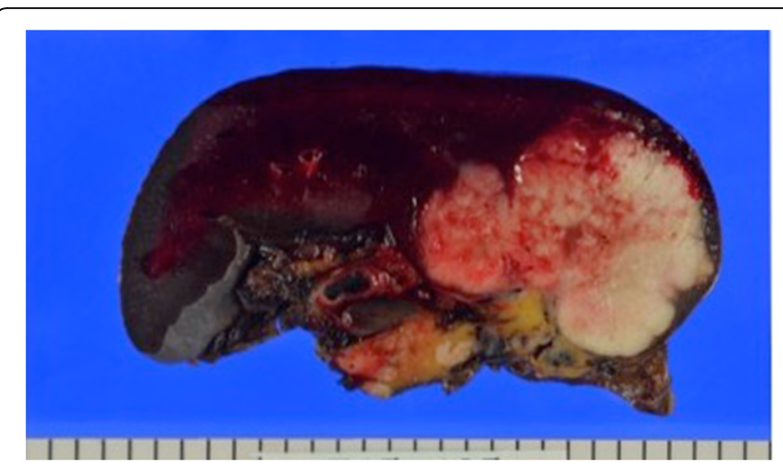

Fig. 4 The resected specimen has a smooth surface and contains a well-circumscribed solid tumor

that the splenic tumor was a moderately differentiated adenocarcinoma, which was very similar to the primary gastric cancer. The immunohistochemistry result of both the gastric cancer and the splenic tumor showed positive for cytokeratin 7, CEA, and negative for cytokeratin 20, p53. These histological and immunochemical findings were consistent with primary gastric cancer and splenic tumor. Therefore, the lesion was diagnosed as metastasis from the previous gastric carcinoma.

The postoperative course was uneventful, and the patient was discharged on postoperative day 21 after the splenectomy. No chemotherapy was administered considering his age, and he was followed-up in the outpatient clinic. The patient remains well to date without recurrence and achieved 5 years of recurrence-free survival after splenectomy for solitary splenic metastatic lesion from gastric cancer.

\section{Discussion and conclusions}

This case highlighted two important issues. Solitary splenic metastasis can occur after the gastrectomy for gastric cancer. Splenectomy is a potentially effective treatment for solitary splenic metastasis when occult metastasis is ruled out by means of several months of follow-up with imaging tests and PET/CT.

The first issue is that a solitary splenic metastasis can occur after the gastrectomy for gastric cancer. Except for leukemia and malignant lymphoma, splenic metastasis is infrequent. Among 4407 autopsy cases associated with malignant metastasis, splenic metastasis was found in 312 cases $(7.1 \%)$, and 22 cases showed splenic metastasis among 536 cases of gastric cancer (4.1\%) [17]. Splenic metastasis from gastric cancer usually presents as one of the multi-organ involvements $[2,3]$, and there are only few case reports about solitary splenic metastasis from gastric cancer. Actually, there is no definitive reason despite several hypotheses for this $[1,2]$. First, the spleen has a poorly developed lymphoid system especially in afferent lymphatic vessels. It is rare for a tumor cell to 


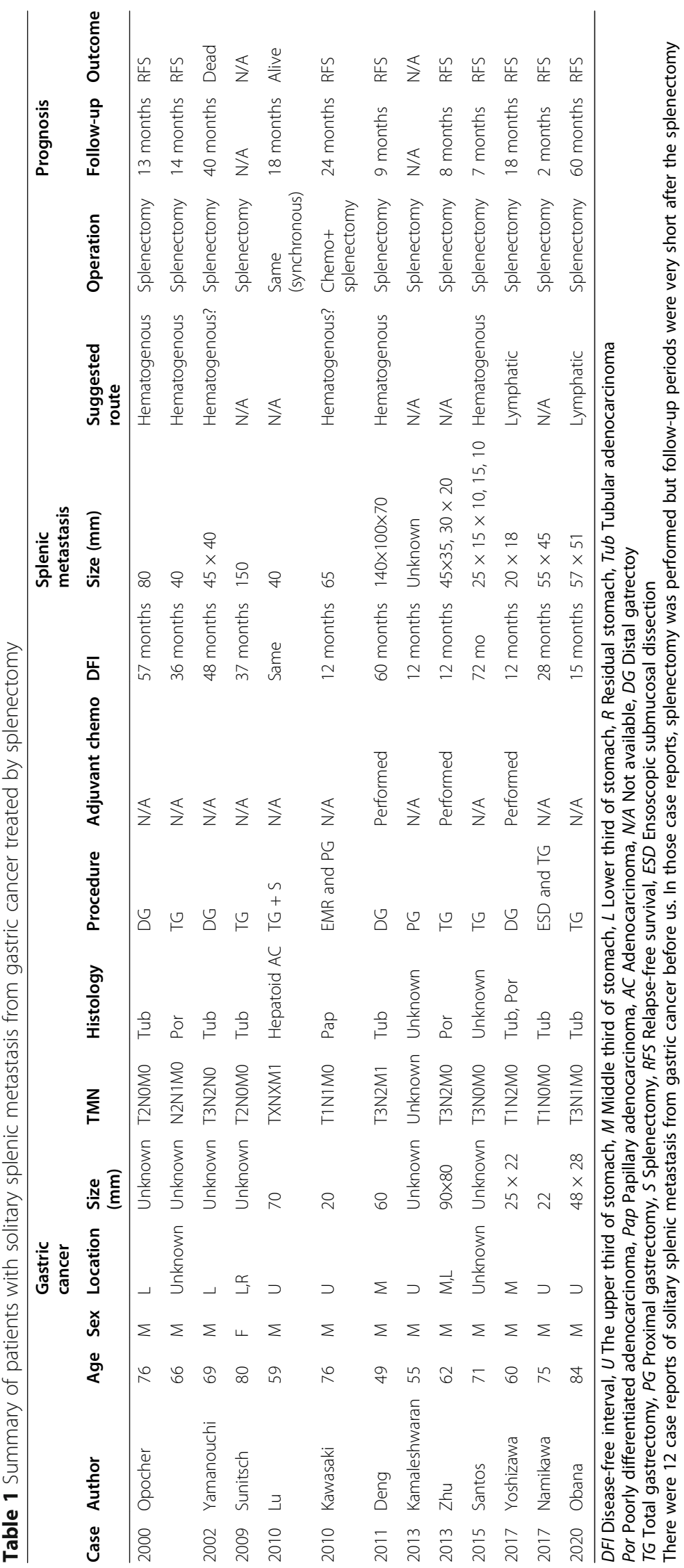


metastasize via the lymphatic route. Second, the splenic artery arises at a sharp angle from the celiac artery. It is very difficult for tumor cells to reach the spleen. Third, the spleen has an immunological antitumor effect and rhythmically constricts to squeeze out tumor cells. When solitary splenic metastasis is suspected, it is expected to be accompanied with multi-organ occult tumor metastases. To differentiate solitary or widespread visceral metastasis, the wait-and-see approach is suggested; follow-up with the suspected patient performing image tests for a couple of months and wait for the growth of occult tumor metastasis [5, 13, 14]. However, there is no consensus about the follow-up interval of the wait-and-see approach before splenectomy. In our case, we strongly suspected the patient to have metastases to sites other than the spleen and thus, performed this wait-and-see approach for almost 6 months before a PET/CT assessment. The PET/CT showed abnormal FDP accumulation in the spleen, and we diagnosed solitary splenic metastasis. With the PET/CT after the waitand-see approach, we differentiated solitary splenic metastasis from widespread visceral metastasis.

The second issue is that splenectomy is a potentially effective treatment for patients with solitary splenic metastasis when multi-organ occult metastasis is ruled out by means of several months of follow-up with imaging tests and PET/CT. There are a reported 12 cases of solitary splenic metastasis from gastric cancer among publications between 2000 and 2020 searched in PubMed [414], and our case is the 13th one achieving the longest recurrence-free survival. Both clinical and pathological details of the previous case reports and present case are described in Table 1 . In all cases, splenectomy was performed, but there is no report describing the long-term follow-up course after splenectomy. One case report followed up with the patient for 40 months after splenectomy, and the patient died of tumor recurrence in the liver and peritoneum [4]. In this case, we assumed this patient might have occult tumor metastasis in areas other than the spleen because the tumor metastasized via the splenic artery. There are three routes through which gastric cancer cells can metastasize to the spleen [18]: splenic vein, splenic artery, and lymphatic vessels. In the splenic vein, blood flows away from the spleen unless the patient has portal hypertension disease, so it is uncommon for tumor cells to reach the spleen against blood flow through the splenic vein. Via the splenic artery, tumor cells have to pass through the systemic circulation to reach the spleen, and in such cases, splenic metastasis would be accompanied by multi-organ metastasis. As for the lymphatic route, it is true that the spleen has poorly developed afferent lymphatic vessels. However, gastric cancer cells can metastasize directly to the spleen, and solitary splenic metastasis from gastric cancer can occur, theoretically. In our case, the gastric cancer was located in the cardia of the stomach near the spleen, and one lymph node near the short gastric artery was positive for metastasis. In addition, pathological findings showed lymphatic invasion but no vascular invasion. Accordingly, we assumed that the gastric cancer metastasized directly to the spleen through the lymphatic route. Therefore, even though the patient did not have adjuvant chemotherapy after the gastrectomy and splenectomy considering his older age, there were no widespread multi-organ metastases and the patient achieved a 5-year recurrence-free survival after the splenectomy.

Though it is a very rare case, splenic metastasis can occur not only from gastric cancer but also from other non-hematopoietic malignancies such as colorectal cancer, ovarian cancer, and lung cancer [19]. Regardless of the primary lesion, splenic metastasis is usually associated with multi-visceral organ metastases. When we suspected a solitary splenic metastasis, we performed a wait-and-see approach first and then performed PET/CT evaluation to rule out other organ metastases before splenectomy.

Solitary splenic metastasis can occur after gastrectomy for gastric cancer. When a solitary splenic metastasis is suspected, the patient should be evaluated with imaging tests for several months to rule out other organ metastasis with PET/CT before splenectomy.

\section{Abbreviations}

CA19-9: Carbohydrate antigen 19-9; CEA: Carcinoembryonic antigen; CT: Computed tomography; FDG: ${ }^{18}$ F-2-deoxy-2-fluoro-glucose; PET: Positronemission tomography

\section{Acknowledgements}

We would like to thank Dr. Shigeyuki Kawa for carefully proofreading this manuscript and providing advice. We are also grateful to Dr. Yuya Sasaki for giving us advice about the structure of this manuscript.

\section{Authors' contributions}

$\mathrm{AO}$ is responsible for the conception and design of the work, and all coauthors contributed to the acquisition and interpretation of the data for the work. AO drafted the work and other coauthors revised it. All authors approved the manuscript to be published and agree to be accountable for all aspects of the work in ensuring that questions related to the accuracy or integrity of any part of the work are appropriately investigated and resolved.

\section{Funding}

None.

\section{Availability of data and materials}

Data sharing is not applicable to this article as no datasets were generated or analyzed during the current study.

\section{Ethics approval and consent to participate}

The ethics review board of Asama Nanroku Komoro Medical Center approved this study. Written informed consent was obtained from the patient for extracting his data from electronic medical chart system. A copy of the written consent is available for review by the Editor-in-Chief of this journal on request. 


\section{Consent for publication}

The patient gave consent for the publication of his information.

\section{Competing interests}

None.

Received: 29 June 2020 Accepted: 10 September 2020

Published online: 19 September 2020

\section{References}

1. Capizzi PJ, Allen KB, Amerson JR, Skandalakis JE. Isolated splenic metastasis from rectal carcinoma. South Med J. 1992;85:1003-5.

2. Lam KY, Tang V. Metastatic tumors to the spleen: a 25-year clinicopathologic study. Arch Pathol Lab Med. 2000;124:526-30.

3. Schon CA, Gorg C, Ramaswamy A, Barth PJ. Splenic metastases in a large unselected autopsy series. Pathol Res Pract. 2006;202:351-6.

4. Yamanouchi K, Ikematsu Y, Waki S, Kida H, Nishiwaki Y, Gotoh K, et al. Solitary splenic metastasis from gastric cancer: report of a case. Surg Today. 2002:32:1081-4.

5. Kawasaki H, Kitayama J, Ishigami H, Hidemura A, Kaisaki S, Nagawa H. Solitary splenic metastasis from early gastric cancer: report of a case. Surg Today. 2010;40:60-3.

6. Deng Z, Yin Z, Chen S, Peng Y, Wang F, Wang X. Metastatic splenic alphafetoprotein-producing adenocarcinoma: report of a case. Surg Today. 2011; 41:854-8.

7. Yoshizawa J, Kubo N, Ishizone S, Karasawa F, Nakayama A. Curative resection by splenectomy for solitary splenic metastasis from early gastric cancer: a case report and literature review. BMC Cancer. 2017;17:436.

8. Namikawa T, Kawanishi Y, Fujisawa K, Munekage E, Munekage M, Sugase T, et al. Metachronous solitary splenic metastasis arising from early gastric cancer: a case report and literature review. BMC Surg. 2017;17:96.

9. Opocher E, Santambrogio R, Bianchi P, Cioffi U, De Simone M, Vellini S, et al. Isolated splenic metastasis from gastric carcinoma: value of CEA and CA 199 in early diagnosis: report of two cases. Am J Clin Oncol. 2000;23:579-80.

10. Sunitsch S, Eberl T, Jagoditsch M, Filipot U, Tschmelitsch J, Langner C. Solitary giant splenic metastasis in a patient with metachronous gastric cancers. South Med J. 2009:102:864-6.

11. Lu CC, De-Chuan C, Lee HS, Chu HC. Pure hepatoid adenocarcinoma of the stomach with spleen and lymph-node metastases. Am J Surg. 2010;199: e42-4.

12. Kamaleshwaran KK, Sivanesan B, Shibu D, Shinto AS. Rare case of isolated splenic metastases from gastric cancer detected with fluorine-18 fluorodeoxyglucose-positron emission tomography/computed tomography. Indian J Nucl Med. 2013;28:119-20.

13. Zhu YP, Mou YP, Ni JJ, Zhou YC, Jiang JW, Jiang ZN, et al. Isolated splenic metastases from gastric carcinoma: a case report and literature review. World J Gastroenterol. 2013;19:5199-203.

14. Santos M, Martins V, Moreno F, Vizcaíno JR, Mesquita I. Splenic metastasis from gastric adenocarcinoma: A rare case. Int I Surg Case Rep. 2015;7C:11923.

15. Japanese gastric cancer treatment guidelines 2014 (ver. 4). Gastric Cancer. 2017;20:1-19. https://www.ncbi.nlm.nih.gov/pmc/articles/PMC5215069/.

16. Japanese Gastric Cancer A. Japanese classification of gastric carcinoma: 3rd English edition. Gastric Cancer. 2011;14:101-12.

17. Berge T. Splenic metastases. Frequencies and patterns. Acta Pathol Microbiol Scand A. 1974;82:499-506.

18. Mainprize KS, Berry AR. Solitary splenic metastasis from colorectal carcinoma. BJS (British J Surg). 1997;84:70.

19. Comperat E, Bardier-Dupas A, Camparo P, Capron F, Charlotte F. Splenic metastases: clinicopathologic presentation, differential diagnosis, and pathogenesis. Arch Pathol Lab Med. 2007:131:965-9.

\section{Publisher's Note}

Springer Nature remains neutral with regard to jurisdictional claims in published maps and institutional affiliations.

Ready to submit your research? Choose BMC and benefit from:

- fast, convenient online submission

- thorough peer review by experienced researchers in your field

- rapid publication on acceptance

- support for research data, including large and complex data types

- gold Open Access which fosters wider collaboration and increased citations

- maximum visibility for your research: over $100 \mathrm{M}$ website views per year

At $\mathrm{BMC}$, research is always in progress.

Learn more biomedcentral.com/submissions 